\title{
EFFECTS OF ELECTRICAL POLARIZATION ON B-TYPE CARBONATED HYDROXYAPATITE
}

\author{
Kazumasa Tanaka ${ }^{1,2}$, Satoshi Nakamura ${ }^{1}$, Katumi Yoshida ${ }^{2}$, \\ Kazuaki Hashimoto ${ }^{2}$, Yoshitomo Toda ${ }^{2}$, Kimihiro Yamashita ${ }^{{ }^{*}}$ \\ Corresponding author: yama-k.bcr@tmd.ac.jp (K. Yamashita) \\ ${ }^{1}$ Institute of Biomaterials and Bioengineering, Tokyo Medical and Dental University \\ 2-3-10, Kanda-surugadai, Chiyoda, Tokyo 101-0062, Japan \\ ${ }^{2}$ Industrial Inorganic Chemistry, Graduate School of Engineering, \\ Chiba Institute of Technology \\ 2-17-1, Tsudanuma, Narashino City, Chiba 275-0016, Japan
}

Keywords: Carbonated hydroxyapatite, Apatite, Electrical polarization, Simulated body fluid

\begin{abstract}
Biological apatite, in bones and teeth as hard tissue in human body, contains a few carbonate ions. Therefore, it isn't completely equal to stoichiometric hydroxyapatite (HA). Chemical solubility for an HA ceramic is especially affected to the carbonate ions in lattice. The purpose of this work has been the investigation of the electrical polarization effect on B-type carbonated hydroxyapatite (CHA) ceramics. B-type CHA was synthesized by wet chemical method, and the CHA was sintered at $800^{\circ} \mathrm{C}$ in carbon dioxide atmosphere. From result of FTIR analyses were shown the carbonate absorption bands belong to substitution for phosphate site (B-type) in the CHA ceramics. The CHA ceramics were polarized with voltage in various high temperatures, and analyzed to estimate the electrical stored charged in the polarized CHA ceramics by thermally stimulated depolarization current (TSDC) measurement. The TSDC spectra of the CHA ceramics showed the maxim current density around at $450-550^{\circ} \mathrm{C}$, respectively. Bioactivities of the polarized $\mathrm{CHA}$ ceramics were evaluated by deposition of bone-like apatites crystals in simulated body fluid (SBF). The SBF immersion test demonstrated that positively charged surface of the CHA ceramic accelerated deposition of the bone-like apatites compared with that of non-polarized CHA ceramic.
\end{abstract}

(Received 23 June 2004; Accepted August 30, 2004)

\section{INTRODUCTION}

Hydroxyapatite (HA) ceramics has been founded that has electrical polarization by proton ions transport with a voltage in high temperature 1. Electrical polarized HA ceramics has two contrastive surfaces, are negatively charged surface ( $\mathrm{N}$-surface) and positively charged surface (P-surface). On the $\mathrm{N}$-surface of HA ceramic, it was demonstrated more accelerate deposition of the bone-like apatites than non-polarized HA ceramic (0-surface) in simulated body fluid (SBF) with nearly equal to human blood plasma. While the P-surface of HA ceramic was decelerate depositions of the bone-like apatite ${ }^{2}$. Thus we expect electrical polarization effect can applied widely to fabrication of the novel bioactive enhancement materials. On the other hand, previous research has been considered to the dipolar movements of sodium-carbonated hydroxyapatite $\left(\mathrm{HCO}_{3} \mathrm{NaAp}\right)$ preheated at 200 and $400^{\circ} \mathrm{C}$ by $\mathrm{H} \mathrm{El}$ Feki et al. ${ }^{3}$ using thermally stimulated current (TSC) measurement at low temperature range of -170 and $160^{\circ} \mathrm{C}$ with electric field of $5 \mathrm{kV} \cdot \mathrm{cm}^{-1}$. According to this report, relaxation phenomena in $\mathrm{HCO}_{3} \mathrm{NaAp}$ associated with hydroxide dipole reorientations in apatitic channels in preheated at $200^{\circ} \mathrm{C}$, and with dielectric manifestation of a structural hexagonalmonoclinic transition in preheated at $400^{\circ} \mathrm{C}$, respectively.

Recently, the carbonated hydroxyapatite (CHA) ceramics are attracted attention in many researchers as applicable using bone replacement materials because it was reported that chemical solubility for the CHA was more superior to HA ceramics. In addition, characteristic of the CHA in chemical composition and structure is more similar to biological apatite in bones and teeth mineral because bones, enamel and dentin contain a various inorganic ions, and carbonate ions are maintained 7.4, 3.5 and 5.6 mass $\%{ }^{4}$.

Substitution of carbonate ions can be take place in two sites of the HA lattice. One is that carbonate ions substituted for hydroxide ions, which was termed A-type. And the other case of the substitution for the phosphate ions was termed B-type. In the past, IR spectra were demonstrated carbonate ions bands presence at 1545,1450 and $880 \mathrm{~cm}^{-1}$ for A-type, and at 1465,1412 and $873 \mathrm{~cm}^{-1}$ for B-type substitution ${ }^{5}$.

In this study, we investigated electrical polarizability and effects of electrical polarization on B-type CHA ceramics by thermally stimulated 
depolarization current (TSDC) measurement and observation bone-like apatites forming ability in SBF. On the SBF immersion test in the presence study, CHA samples that polarized at $350^{\circ} \mathrm{C}$ in dc field were used.

\section{EXPERIMENTAL PROCEDURE}

B-type CHA was prepared using a modification of the reported method ${ }^{6}$. Calcium nitrate tetrahydrate 1.0 $\mathrm{M}\left(\mathrm{Ca}\left(\mathrm{NO}_{3}\right)_{2} \cdot 4 \mathrm{H}_{2} \mathrm{O}\right.$, Kantokagaku Co.) solution was added to the $0.15 \mathrm{M}$ disodium hydrogenphosphate $\left(\mathrm{Na}_{2} \mathrm{HPO}_{4}\right.$, Wako Co.) solution containing $0.6 \mathrm{~mol}$ sodium carbonate $\left(\mathrm{Na}_{2} \mathrm{CO}_{3}\right.$, Wako Co. $)$ was maintained at $90^{\circ} \mathrm{C}$ and $\mathrm{pH}$ was maintained at $9.0 \pm$ 0.1 with $1 \mathrm{~N}-\mathrm{HCl}$.

Obtained CHA powder was formed disks and sintered at $800^{\circ} \mathrm{C}$ in carbon dioxide atmosphere for $2 \mathrm{~h}$ to minimize carbonate loss from surface of the CHA. Sintered CHA ceramics were characterized crystalline structure and confirming of substitution site on the carbonate ions in HA lattice by $\mathrm{X}$-ray diffraction (XRD: PHILIPS PW-1700) with $\mathrm{CuK} \alpha$ radiation at $40 \mathrm{kV}$ and $10 \mathrm{~mA}$ and Fourier transforms infrared spectra (FTIR: JEOL Diamond-20 FT-IR spectra photometer) in the range of $4000-400 \mathrm{~cm}^{-1}$. The CHA ceramics was sandwiched with pair of platinum electrodes, which was electrically polarized at high temperatures in dc field.

TSDC was measured at temperature from room temperature to $700^{\circ} \mathrm{C}$ with rate of heating temperature is $5^{\circ} \mathrm{C} \cdot \mathrm{min}^{-1}$. The polarized $\mathrm{CHA}$ ceramics were immersed in SBF, and were keeping at $37^{\circ} \mathrm{C}$ in incubator. After immersion in SBF, the 0-, $\mathrm{N}$ - and P-surface of the CHA ceramics were observed scanning electron microscopy (SEM: JEOL JSM-6300).

\section{RESULTS AND DISCUSSION}

The XRD pattern of the CHA sintered at $800^{\circ} \mathrm{C}$ in carbon dioxide gas shows in Fig. 1. The XRD pattern of CHA ceramics indicated no phase other than HA (JCPDS No.09-0432), but diffraction peaks of the (002) and (300) refractions in CHA ceramic shifted to the lower and higher angle than peak position of the HA, respectively. This result indicated that carbonate ion substituted for the part of phosphate ion site. And then, lattice of parameters of CHA ceramic were demonstrated $\mathrm{a}=0.935(6) \mathrm{nm}$ and $\mathrm{c}=0.6933(2) \mathrm{nm}$ by least-squares fitting. It was revealed that change the reducing of a-axis and the expanding of the c-axis, from comparison with the lattice parameters of synthesized HA ceramics $(\mathrm{a}=0.9420(5) \mathrm{nm}$ and $\mathrm{c}=$ $0.6885(3) \mathrm{nm}$ ). From this tendency for the result of changing lattice parameters in the CHA were in agreement with the past reports ${ }^{7,8}$, which indicated that carbonate ions substituted for the phosphate site in HA lattice. Density of the CHA ceramics powder was found to be $3.03 \mathrm{~g} \cdot \mathrm{cm}^{-3}$ calculated using a pycnometer,

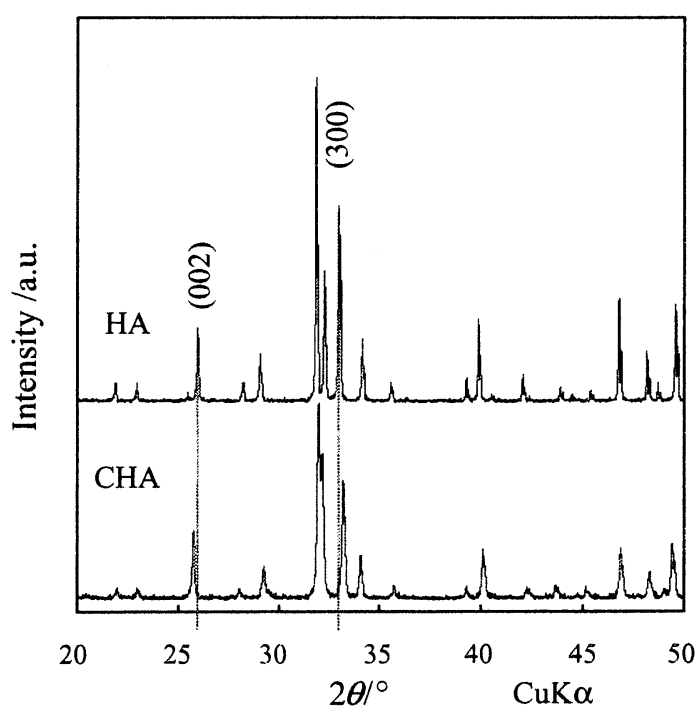

Fig. 1 XRD patterns of the sintered HA ceramic and the sintered $\mathrm{CHA}$ ceramic at $800^{\circ} \mathrm{C}$ in carbon dioxide atmosphere.

and its value is lower than that of theatrical value of HA $\left(3.16 \mathrm{~g} \cdot \mathrm{cm}^{-3}\right)$. And relative density of the CHA sintered at $800^{\circ} \mathrm{C}$ for $2 \mathrm{~h}$ in carbon dioxide atmosphere was approximately $92.7 \%$.

Fig. 2-(a) and 2-(b) shows the FTIR spectra of the $\mathrm{CHA}$ ceramics and after the polarization $\mathrm{CHA}$ ceramics. The IR spectra of the CHA produced the carbonate absorption bands at 1415,1450 and $871 \mathrm{~cm}^{-1}$ and very weak hydroxyl ion band at $3571 \mathrm{~cm}^{-1}$ (not shown). From the IR result, it was demonstrated that carbonate ions were substituted for phosphate ions and the carbonate ions were maintained in the HA structure after the electrical polarization.

The TSDC measured at various electrical polarization temperatures are shown in Fig. 3. The non-polarized CHA ceramics was not observed depolarization peak. On the other hands, the polarized CHA ceramics showed depolarization currents, which is increasing at approximately $250^{\circ} \mathrm{C}$, and achieved at maximum depolarization current and gradually decreased. The amounts of stored electrical charges (Q) by electrical polarization were calculated from integration of depolarization current curve area.

The $Q$ values for electrical polarization temperatures of 300,350 and $400^{\circ} \mathrm{C}$ were $3.1,15.6$ and $31.9 \mathrm{mC} \cdot \mathrm{cm}^{-2}$, respectively, and these $Q$ values tended to increase with increasing of polarization temperature. The results also indicate that these $Q$ values of the CHA ceramics were larger than the reported $\mathrm{Q}$ value of $\mathrm{HA}$ ceramic $\left(\mathrm{Q}=10.5 \mu \mathrm{C} \cdot \mathrm{cm}^{-2}, \mathrm{HA}\right.$ polarized at $300^{\circ} \mathrm{C}$ in dc field of $\left.2 \mathrm{kV} \cdot \mathrm{cm}^{-1}\right){ }^{1}$. As the result, it was found that the CHA ceramics can be electrical polarization and the stored electrical charges can be controlled with polarization temperature. 

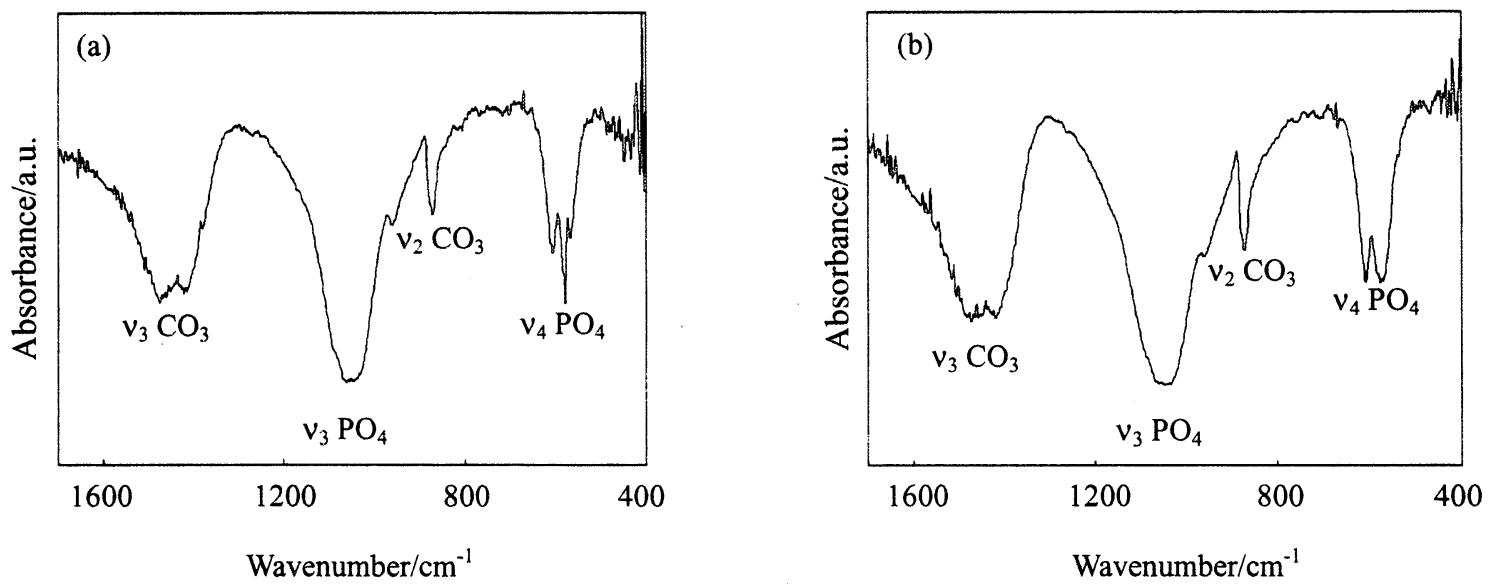

Fig. 2 FTIR spectra of the CHA ceramics before the electrical polarization (a) and after the electrical polarization (b).

The calculated activation energy $\left(E_{a}\right)$ for the depolarization of $\mathrm{CHA}$ ceramic was approximately $1.3 \mathrm{eV}$, and the $\mathrm{E}_{a}$ value was higher than that of the HA ceramic $\left(\mathrm{E}_{a}=0.84-0.89 \mathrm{eV}^{1}\right)$. In addition, the $\mathrm{E}_{a}$ of the CHA was nearly equal to the activation energy caused by oxide ions immigration in $c$-axis, comparison with report by $\mathrm{H}$. Owada et al. ${ }^{9}$. They have reported that calculated activation energy of the yttrium substituted oxyhydroxyapatite [Y-CaHAp] that didn't contain hydroxyl ions was approximately $1.5 \mathrm{eV}$ with conduction of $\mathrm{O}^{2-}$ ions. Therefore, we might be

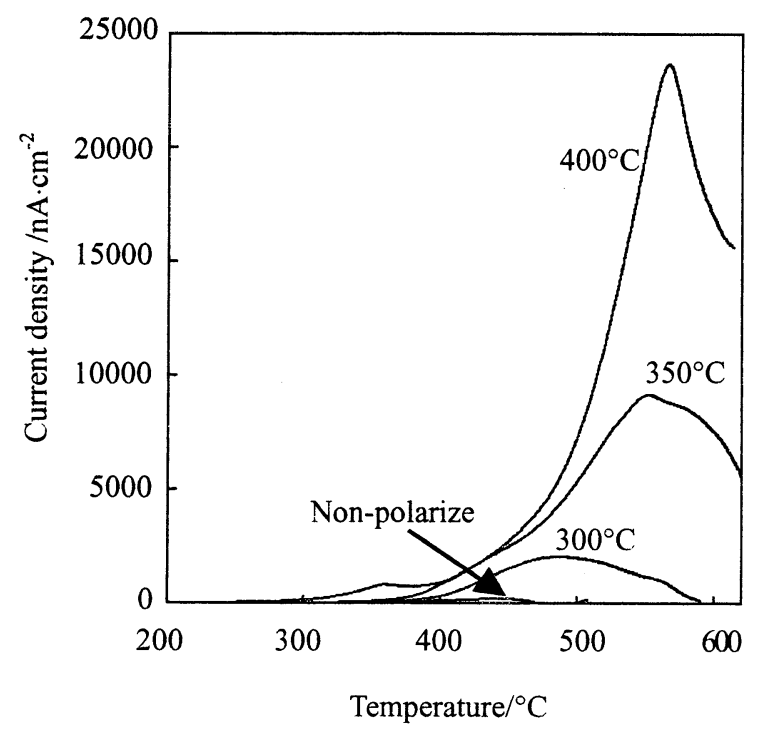

Fig. 3 TSDC spectra of the non-polarized CHA ceramic and the CHA ceramics polarized at 300,350 , and $400^{\circ} \mathrm{C}$ in dc electrical fields. suggested that the carrier ions in the $\mathrm{CHA}$ were $\mathrm{O}^{2-}$ ions other than $\mathrm{H}^{+}$(proton) ions because the hydroxyl ion band in IR spectrum of CHA ceramic was very weak. Additionally, the reason, the electrical stored charges of $\mathrm{CHA}$ ceramics larger than the HA ceramic, was thought to be due to immigrations of $\mathrm{O}^{2-}$ carrier ions.

The SEM photographs of the 0 -, $\mathrm{N}$ - and P-surface of CHA ceramics, immersed in SBF of $30 \mathrm{ml}$ for $1 \mathrm{~d}$ at $37^{\circ} \mathrm{C}$, shows in Fig. 4. The all samples, the 0-, N-, and P-surface of CHA ceramics were observed bone-like apatite depositions on their surfaces after immersion of 1d. As can be seen from Fig.4, the bone-like apatite crystals on the P-surface were built up lamination layer, comparisons with that on the 0 - and $\mathrm{N}$-surface. The results indicates that the P-surface of the $\mathrm{CHA}$ accelerate the bone-like apatites deposition ability. The reason of acceleration growth of bone-like apatites on the P-surface was considered in this below.

Assuming that the CHA ceramic is dissolved in $\mathrm{SBF}$, carbonate ions that substituted in the CHA lattice are releasing from the surface of $\mathrm{CHA}$ to the SBF. And then, the carbonate ions $\left(\mathrm{HCO}_{3}{ }^{-}\right)$in the $\mathrm{SBF}$ were induced to the positively charged surface of $\mathrm{CHA}$ ceramic. Therefore, the concentration of carbonate ions nearby the P-surface of $\mathrm{CHA}$ ceramics was increased and become higher than that of the 0 - and the N-surface. A. Oyane et al. ${ }^{10}$ had demonstrated that the SBF (r-SBF and i-SBF) which has high carbonate ions concentration more than conventional SBF (c-SBF), were produced to the calcium carbonate clusters with hydrodynamic diameters of $10-30 \mathrm{~nm}$ other than calcium phosphate clusters with hydrodynamic diameter of $\sim 1 \mathrm{~nm}$, because carbonate ions concentration in the r-SBF and i-SBF were supersaturated with respect to calcite cluster. Judging from this report, we estimated that calcium carbonate clusters were presented on the P-surface with attracted 

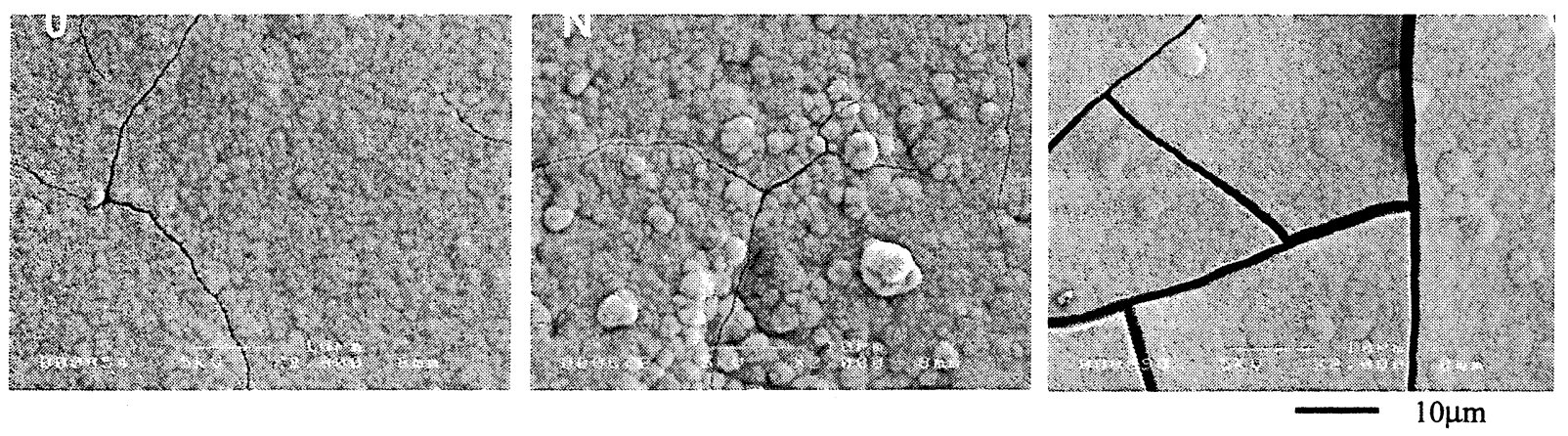

Fig. 4 SEM photographs of the surfaces of the non-polarized (0-surface), the negatively charged surface ( $\mathrm{N}$-surface) and the positively charged surface ( $\mathrm{P}$-surface) of $\mathrm{CHA}$ ceramics that were immersed in SBF for $1 \mathrm{~d}$.

carbonate ions $\left(\mathrm{HCO}_{3}^{-}\right)$. Consequently, we suggested that the formation of calcium carbonate clusters on the P-surface of CHA ceramic may lead to forming and growth of the bone-like apatite crystals in SBF.

\section{CONCLUSIONS}

The synthesized CHA ceramic in the presence study was characterized only HA crystalline and most carbonate ions substituted for phosphate ion site (B-site) in HA structure by XRD and FTIR analyses. Electrical polarization for the CHA ceramics could be controlled by a polarization temperature with TSDC measurement. The result of SBF immersion tests for 1d immersion period demonstrated that the positively charged surface of the CHA ceramic accelerate the growth of bone-like apatites, comparison with non-polarized surface of CHA ceramic.

\section{REFERENCE}

1. S. Nakamura, H. Takeda, K. Yamashita. Proton transport polarization and depolarization of hydroxyapatite ceramics, J. Appl. Phys., 89, 5386-5392 (2001).

2. K. Yamashita, N. Oikawa, T. Umegaki., Acceleration and deceleration of bone-like crystal growth on ceramics hydroxyapatite by electric poling, Chem. Mater., 8, 2697-2700 (1996).

3. H El Feki, A Ben Salah, A Daoud, A Lamure and C Lacabanne, Studies by thermally stimulated current (TSC) of hydroxyl- and fluoro-carbonated apatites containing sodium ions, J. Phys.: Condens Matter., 12, , 8331-8343. (2000).

4. LeGeros RZ., Calcium phosphstes in oral biology and medicine, Basel, Switzerland: Karger AG,
(1991).

5. Elliott JC, The interpretation of the infra-red adsorption apectra of some carbonate-containing apatites, Stack MV, Fearnhead RW (eds) Tooth enamel. John Wright, Brisol, 20-22 (1965).

6. Y. Doi, $\mathrm{T}$ Koda, N Wakamatu, $\mathrm{T}$ Goto, $\mathrm{H}$ Kamemizu, Y Moriwaki, M Adachi, and Y Suwa, Influence of carbonate on sintering of apatites, $J$. Dent. Res., 72(9), 1279-1284 (1993).

7. LeGeros, R.Z. Crystallographic studies on the carbonate substitution in the apatite structure; thesis New York University, (1967).

8. D. G. A. Nelosn and J. D. B. Featherstone, preparation, analysis, and characterization of carbonated apatites, Calcif. Tissue Int., 34, S69-S81 (1982).

9. H. Owada, K. Yamashita, T. Umegaki, T. Kanazawa, M. Nagai, Electrical properties of apatite ceramics with a microstructure controlled by $\mathrm{Y}^{3+}$ substitution, Yogyo-Kyokai-Shi, 94, 837-848 (1986).

10. A. Oyane, K Onuma, A Ito, Hyun-Min Kim, T Kokubo and T Nakamura, Formation and growth of clusters in conventional and new kinds of simulated body fluids, J. Biomed. Mater. Res., 64A, 339-348 (2003). 